\title{
Knowledge of results and cautiousness in signal detection
}

\author{
Lawrence C. Hartlage \\ KENTUCKY DEPARTMENT OF MENTAL HEALTH
}

\begin{abstract}
Sixteen Ss were tested on the Rotter Level of Aspiration Board and classified as cautious or non cautious. A tone masked by white noise was presented to Ss at their respective RL's on 30 of 60 trials, with 30 blank trials. Non cautious Ss made significantly more false positive errors than did cautious Ss. With knowledge of results, both cautious and non cautious Ss made fewer errors but non cautious Ss still made significantly more errors than the cautious Ss.
\end{abstract}

\section{Introduetion}

Broadbent \& Gregory (1963), requiring observers to respond to faint auditory signals with a rating of certainty as to their presence, found a significant trend toward cautiousness in reporting over time. Although a number of investigators have found an increased probability of detection with knowledge of results (Baker, 1959; Weidenfeller, Baker, \& Ware, 1962), the influence of subjective cautiousness present at the onset of a given detection task has received little attention, (Eshbaugh \& Friedman, 1964). The purpose of this study was to concentrate on the difference between cautious and non cautious Ss in the reporting of an auditory signal under conditions where the likelihood of guessing would be high, with and without knowledge of results (KOR).

\section{Subjects}

Ss consisted of 16 undergradutate students enrolled in Introductory Psychology courses at the University of Louisville. These 16 Ss were randomly selected from a group of 42 students who had recently been tested on the Rotter Level of Aspiration Board (Rotter, 1942), and subsequently had been classified as cautious or non cautious. All Ss were participating in experiments as part of their course requirements. Five Ss were males, eleven were females with three males classified as non cautious and two males classified as cautious by their scores on the Rotter Level of Aspiration Board. Apparatus

A Jackson Audio-Oscillator model 655 was used to provide the tone, which was fed through a HewlettPackard 5 watt $600 \mathrm{Ohm}$ attenuator, through a telegraph key and into a Grason-Stadler model 829-D electronic switch. From the electronic switch the tone fed into a mixer, where it was combined with an unattenuated noise from a Grason-Stadler white noise generator, and presented to the Ss, ears through a set of S.G. Brown $600 \mathrm{Ohm}$ earphones, type K. A 15 watt unshaded red light was installed on a 20 in by 24 in panel at eye level in front of the chair where the Ss were seated, and the time for both the duration of light and the tone was controlled by a Hunter Klockounter model 120A. The Ss were seated in a desk-type straightback hardwood chair in a room $7 \mathrm{ft} 7$ in long, $6 \mathrm{ft} 8$ in wide, and $8 \mathrm{ft}$ 5 in high. They were separated from the experimenters and all experimental apparatus (excluding the earphones and red warning light panel) by a partition.

\section{Procedure}

Each S's RL was determined by the method of limits (Underwood, 1949) with 10 ascending and 10 descending trials for a $1000 \mathrm{cps}$ tone with a background of white noise. For this range of frequencies fatigue was not considered to be operative to any significant degree, especially since the total session lasted fewer than $20 \mathrm{~min}$. (Hirsh, 1952). Following the instructions presented verbally to the Ss prior to each experimental session, the Ss were presented with 60 trials, 30 without information feedback concerning the correct response, and 30 with information feedback. Fifteen trials in each of the 30 trial series were blank: 15 contained a tone at the individual S's threshold. The electronic switch was used to assure that the rise time of the tone was slow enough to eliminate audible clicks with the signal presentation. The red light in front of the Ss was manually activated at irregular intervals selected from a table of random numbers for durations of $5 \mathrm{sec}$, each activation consisting of a trial. For the second series of trials, after the $S$ had responded the light was manually activated twice after each correct response, and was not activated for an incorrect response. The duration of the light indicating a correct identification was approximately $1 / 2$ sec.per each of the two activations. Each $\mathrm{S}$ was tested in one session of approximately $20 \mathrm{~min}$. duration, including instructions.

\section{Instructions}

Part I: At irregular intervals during the experimental session the red light in front of you will be turned on for a duration of $5 \mathrm{sec}$. During this time you may or may not hear a tone through the earphones. If you hear a tone on a given trial report "yes" after the light goes out. If you do not hear a tone on a given trial report "no" when the light goes out. There will be 30 of these $5 \mathrm{sec}$. trials. You will hear some noise in your earphones throughout the course of the experiment. Any questions?

Part II: In this portion of the experiment you will respond just as you did in the last, except that this time 
you will be told the correct response immediately after you have made your response. If your response was correct, the light will flash twice. If your response was not correct, no light will appear. Any questions?

\section{Results}

Non cautious Ss made more false positive errors than cautious Ss both with $(\mathrm{p}<.005)$ and without $(\mathrm{p}<.001)$ knowledge of results. Although both groups tended to reduce the number of errors with knowledge of results, the differences between the two groups were still significant. It appears that the classifications of Ss as cautious and non cautious is a more accurate predictor of the likelihood of false positive responses than is the knowledge of results.

\section{References}

BAKER, C. H. Toward a theory of vigilance. Canad. J. Psychol., $1959,13,35-42$.

BROADBENT, D. C., \& GREGORY, M. Vigilance considered as a statistical decision. Brit. J. Psychol., 1963, 54, 309-323.

ESHBAUGH, R. N., \& FRIEDMAN,S.R. The Rotter level of aspiration task: A validity study. Psychon. Sci., 1964,1, 341-342.

HIRSH, I. J. The measurement of hearing. New York: McGraw-Hill, 1952. P. 364

ROTTER, J. B. Level of aspiration: a method for the study of personality II: development and evaluation of a controlled method. J. exp. Psychol., 1942, 31, 410-421.

UNDERWOOD, B. J. Experimental psychology. New York: AppletonCentury-Crofts, 1949. Pp. 46-56.

WEIDENFELLER, E. W., BAKER, R. A。, \& WARE, J. R. Effects of knowledge of results (true and false) on vigilance performance. Percept. mot. Skills, 1962, 14, 211-215.

\section{Comment}

In a recent article, Lachman \& Field(1965) state that recognition is more sensitive than recall in measuring retention only in the early stages of serial verbal learning, and is less sensitive than recall in later stages. They suggest that prior findings of the superiority of recognition were due to an artifact of multiple-choice tests.

Unfortunately, the experiment cited by them appears to make the superiority of recall an artifactual result. Stimulus materials were 50 different words, presented singly, but in a constant order which was a n high approximation to English. Such a structure would have high associative contingencies between consecutive words and would make it likely that the Ss would "chunk" or "chain" the words into phrases or sentences. This probability is recognized by Lachman and Field in their concluding paragraph, but I feel they missed its vital importance to the direction of their results.

The Ss were given the words sequentially, and told to memorize them. In all likelihood, they attempted to memorize them in the order presented, and thus obtained feedback (during all trials after the first) as to whether or not they had correctly anticipated each word as it appeared. For high-order approximations to English, it is not surprising that the Ss memorized a 50-word sequence perfectly in about 8-16 trials. When tested for recall after 16 trials, the Ss simply wrote the sequence which they had memorized. (Lachman and Field do not say whether the recall sequence was correct, but I am assuming that it was.) When tested for recognition with the stimulus words presumably out of order (or at least randomly interspersed with "new" words), the Ss were unable to search the entire sequentiallymemorized list of 50 words within the time limit of 1.5 sec., and thus missed about 10 of the 50 words, nearly independently of the number of training trials received. For these latter Ss, it might be justifiable to call the training trials "inappropritate training, " as they specifically prepared the Ss for sequential recall, rather than recognition..

With the same stimulus materials used in this experiment, if the Ss had been allowed unlimited time to decide "recognize" or "don't recognize"-enabling them to recite the entire 50- word list if they had it perfectly memorized-then recognition scores should be as high or higher than recall.

On the other hand, if the sequence of stimulus words consisted of a zero-order approximation to English, recall scores should drop below those for higherorder approximations (Miller \& Selfridge, 1950) and might never equal recognition scores even under the experimental procedure used by Lachman and Field (paced recognition, unpaced recall).

These hypothetical results are just that, and thus do not decrease the empirical probability of the conclusions drawn by Lachman and Field. Their conclusions, however, do not follow logically from their experimental results.

David E. Clement

References Carnegie Institute of Technology

LACHMAN, R., \& FIELD, W. H. Recognition and recall of verbal material as a function of degree of training. Psychon. Sci., 1965, $2,225-226$.

MILLER, G. A., \& SELFRIDGE, J. A. Verbal context and the recall of meaningful material. Amer. J. Psychol., 1950, 63, 176-185. 